\title{
Analyses of local ingredients and dishes on menus of the
}

\section{Budapest-Middle-Danube touristic region}

\author{
Dénes Sándor \\ (Faculty of Commerce, Catering and Tourism, Budapest Business School, Budapest 1054, Hungary)
}

\begin{abstract}
The background of the study is based on previous studies dealing with the areas of Transdanubia of Hungary. Those works have proved the hypothesis of author that local ingredients and dishes represent minimum role on menus. The question is how similar or different the choice of menus of Budapest-Middle-Danube compared with the previously examined areas of Hungary. There can be another question about the usage of local ingredients available near to the catering units. This piece of work has studied 79 menus of Budapest-Middle-Danube, Hungary. The material was collected from different types of restaurants, small restaurants (vendéglő in Hungarian) and roadside restaurants (csárda in Hungarian). The method of the work was on the one hand, data collecting, and on the other hand, examination of the differences between the catering units in details: the number of dishes, the right order of dishes, the appearance of local ingredients and dishes, the consideration of seasonality, the usage of different cooking methods and group of dishes. The study reflects the main problems of countryside restaurants in Hungary. Only minimum number of dishes could be connected to local dishes out of more than thousands. All in all, dishes are not as precise and perfect as the "old ones", so that is why it is important for every expert keep the traditions alive in daily routines and strategic mean too.
\end{abstract}

Key words: menu analysis; local raw materials and dishes; Budapest-Middle-Danube touristic region

\section{Introduction}

The relevance of the topic is given by the global advance in tourism highlighting the choice of dishes offered by catering units. The length of stay for domestic and foreign guests may range from one day to multiple weeks, and consequently the number of occasions they have meals also varies. At the same time, a guest staying one night takes a single hotel service but usually has meals three times. Restaurants, small restaurants (vendéglö in Hungarian) and roadside restaurants (csárda in Hungarian) should preferably offer regional dishes - prepared at least partly from local raw material — in their menu.

The analysis of the studied topic is a current issue since, in accordance with a present hypothesis, one of the problems is that procuring raw materials is much easier and cheaper in hypermarkets. This is the reason why catering companies partly do their shopping in these commercial units and do not spend time on finding local products. Another problem is that local producers cannot always guarantee a constant level of quality and quantity of requested products. Lack of regional dishes appearing in the menu of catering units poses an additional problem.

Bases of the literature background "Appearance of regional dishes in the food choice of the Southern Transdanubian Touristic Region” (Sándor, 2008) and "Analysis of Transdanubian Supply of Dishes_local raw

Dénes Sándor, principal lecturer, Faculty of Commerce, Catering and Tourism, Budapest Business School; research field: menu analysis. 
materials, dishes" (Sándor, 2009a) provide proper ground for the present study focusing on the similar characteristics of the Budapest-Middle-Danube Touristic Region. Earlier works covering the Southern Transdanubian region and the entire Transdanubia play an insignificant role in the restaurant menus.

A professional paper featuring an important collection of catering traditions says: "With the process of river regulation, draining marshlands and also with the development of agrarian culture, growing, collecting and using certain foods simply 'went out of fashion'; these plants, however, used to be important raw materials of cooking and eating, including: buckwheat, turnip, millet, mangel, trapa natans, pumpkin seed oil, pickled carrot, spined loach fish, old herbs etc." (Szigeti, 1999, p. 13). Additional traditional and regional agricultural and food industry products are presented in the professional study (Farnadi (Ed.), Hagyományok, Ízek \& Régiók, 2002).

Present study tries to give an answer to the question how the choice of dishes in the hot cuisine catering units of Budapest-Middle-Danube region differs from that in the previously studied ones. It is also a question whether catering people of the region take advantage of procuring and using locally grown fruits and vegetables. Hungary has gastronomic traditions we should take care of by including authentic local foods and dishes of the region in catering units' menus.

\section{Goals}

The study aims to present the menu supply of the Budapest-Middle-Danube Touristic Region in the years 2005-2008 by a field research of a non-representative sample. The main goal is to survey the choice of dishes and then to evaluate the supply of diverse hot cuisine units-restaurants, small restaurants and roadside restaurants - by professional aspects. Accordingly, we may have a view of the quantitative and qualitative parameters of the dishes listed on the menus.

Among others, the analysis covers the logical dish grouping and listing system, the number of dishes, the diverse use of raw materials and preparation methods, and the supply of local specialities, traditional foods, creative menu compilations and explanation of ambiguous denominations used in menus.

\section{Research methods}

The analysis of the choice of dishes is based on the menus of 50 restaurants, 18 small restaurants and 11 road restaurants used in the years 2005-2008. Catering units were randomly selected by a non-representative sample of the Budapest-Middle-Danube Touristic Region. Fig. 1 shows the distribution of studied catering units.

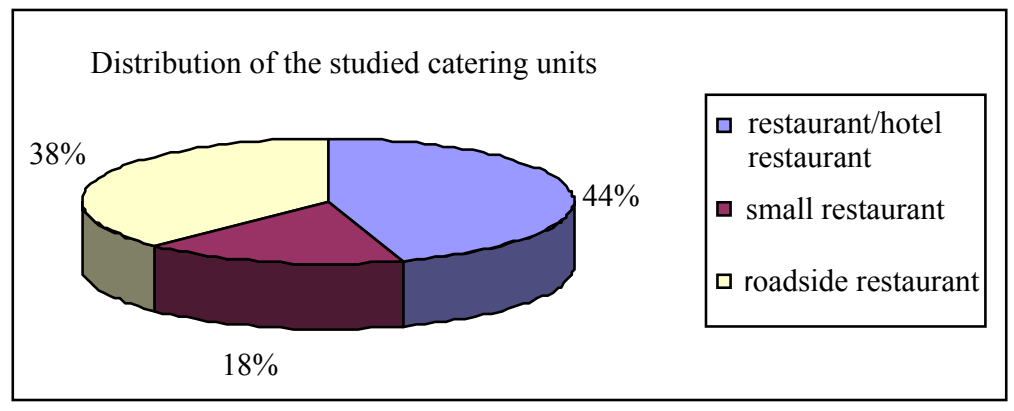

Fig. 1 Distribution of studied catering units

Data source: own research. 
After electronically recording the names and quantity of dishes listed on the menus, meals of certain dish groups were aggregated. Next, the average number of meals in each dish group was calculated with handling different types of catering units (restaurants, small restaurants and roadside restaurants) separately. To provide a more efficient visualization, several diagrams are included to present different distributions and average values. Dish groupings and dishes of the menus can be examined by their total and average numbers.

The total figures of soups, cold and hot starters (50 restaurants, 18 small restaurants and 11 roadside restaurants) show that the average number of cold starters by types of catering units is as follows: 5 in restaurants; 3 in small restaurants and roadside restaurants (see Fig. 2). The average number of soups is 7 in restaurants and 9 in small restaurants and roadside restaurants. The range of soups, i.e., the average number of soups on menus shows that preparing and offering 7-9 different soups might be too much. In case of hot starters, their average number is 3 in restaurants and in small restaurants and roadside restaurants. The number of cold and hot starters is sufficient in all the three types of studied units.

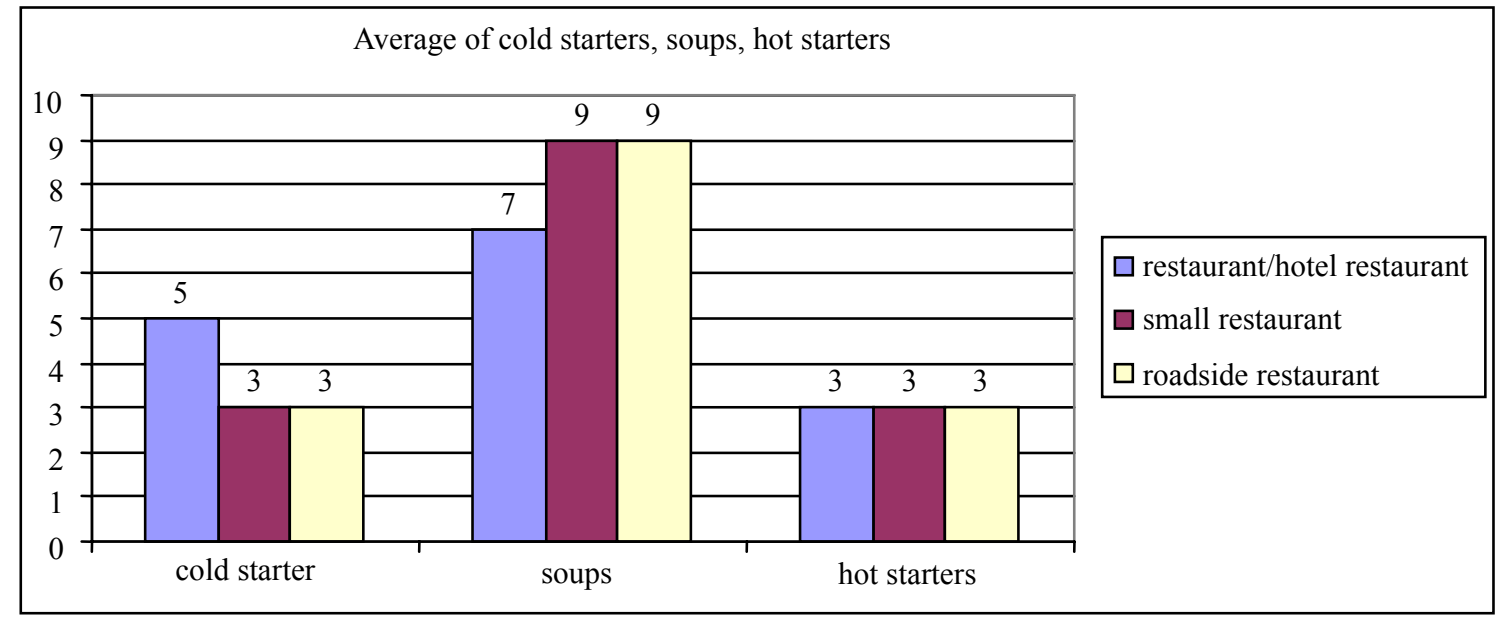

Fig. 2 Average number of soups, cold and hot starters in the different hot cuisine units

Data source: own research.

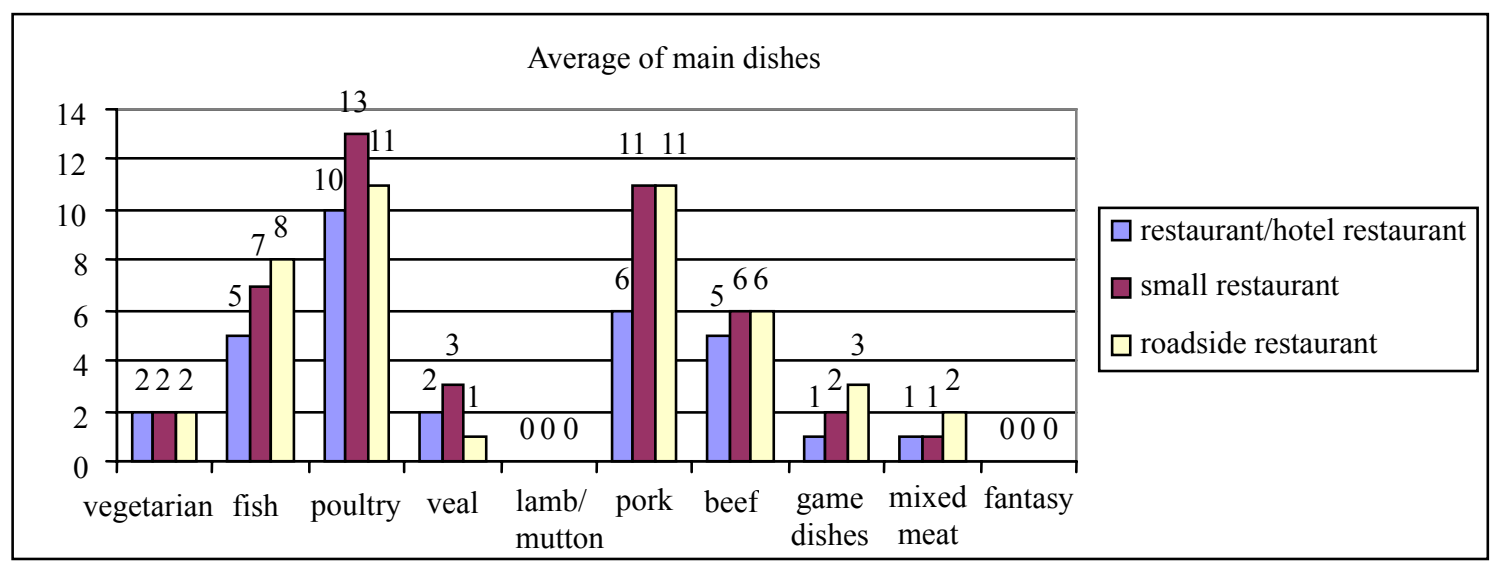

Fig. 3 Average number of main dishes in restaurants, small restaurants and roadside restaurants

Data source: own research.

Fig. 3 shows the average number of main courses in restaurants, small restaurants and roadside restaurants in 
the Budapest-Middle-Danube. Accordingly poultry and pork dishes are the most popular with an average supply of 10 different dishes. Note that a typical small restaurant enlists 13 different dishes of poultry on its menu, while the same figure for restaurants 10 and roadside restaurants are 11. Pork dishes are followed by dishes made of fish, beef, veal, game and vegetarian dishes with an average range of 7, 6, 2, 2, 2 dishes, respectively.

Fig. 4 presents the distribution of dishes offered as main courses in restaurants. Dishes prepared of poultry amount to $31 \%$, while fish, pork and beef dishes give altogether $51 \%$ of the main courses. Dishes made of the above four types of meat provides accordingly $82 \%$ of the total main course supply. These meals are dominated by poultry and only $18 \%$ of main courses include vegetarian, veal, lamb/mutton, game dishes etc.

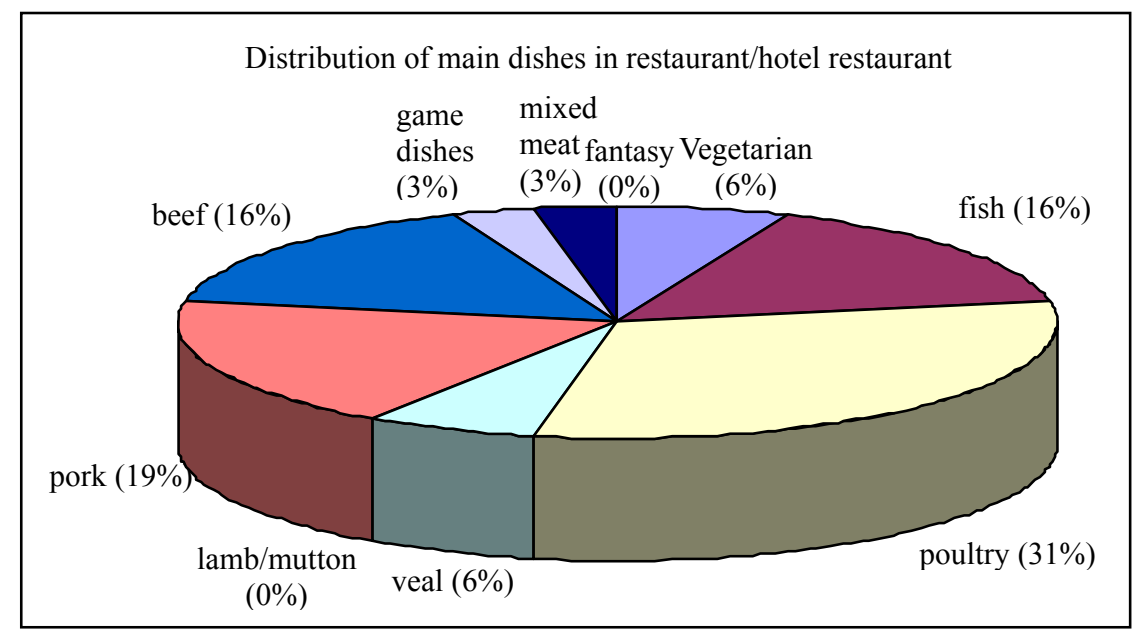

Fig. 4 Distribution of main dishes in restaurants

Data source: own research.

Fig. 5 shows the distribution of main dishes in small restaurants. Poultry dishes give $30 \%$ of the total range, pork dishes amount to $24 \%$, dishes made of fish contribute with $16 \%$ to total main dishes, and beef dishes are responsible for $13 \%$, while vegetarian dishes account for $4 \%$ of total supply. However, only $13 \%$ of space remains for other categories of main courses, which allows for a quite limited range of other meals.

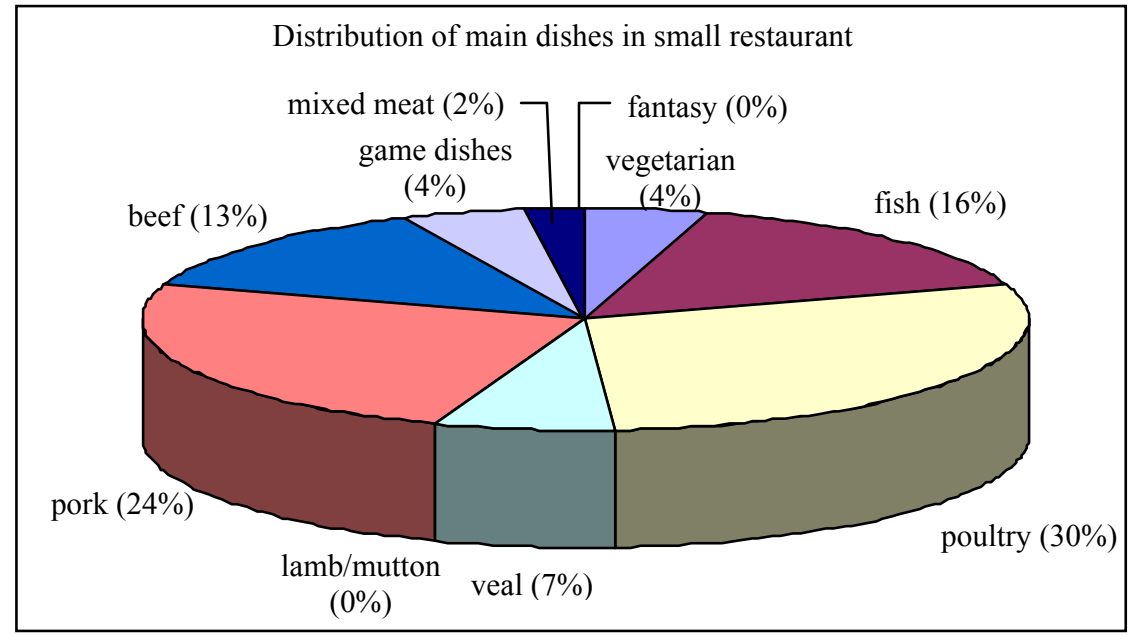

Fig. 5 Distribution of main dishes in small restaurants

Data source: own research. 
Fig. 6 shows the distribution of main course meals in roadside restaurants. Pork, poultry and fish dishes amount to two thirds of total main course supply. The high number of fish dishes, amounting to $18 \%$ of all main courses, comes from roadside fish restaurants. The high number of pork and poultry dishes appropriately reflects the balance of demand and supply. However, only a quite narrow choice remains for other dish categories.

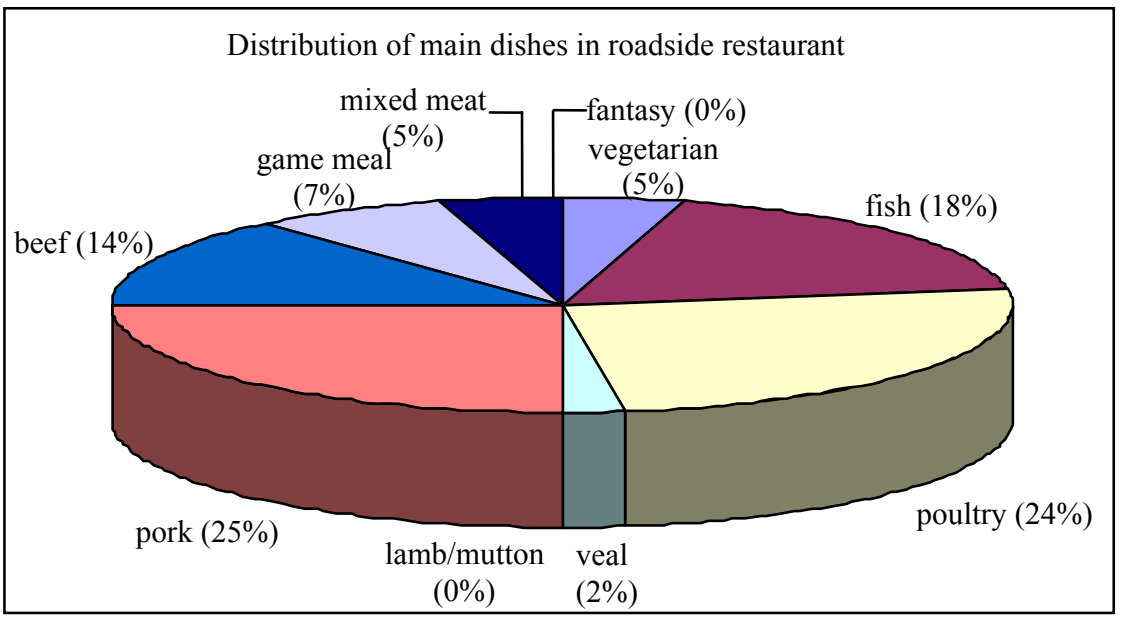

Fig. 6 Distribution of main dishes in roadside restaurants

Data source: own research.

The total amounts of garnishes, Hungarian type of vegetables, salads and sauces (50 restaurants, 18 small restaurants and 11 roadside restaurants) indicate that the average number of different garnishes is 5 in restaurants, 7 in small restaurant and 8 in roadside restaurants (see Fig. 7). The average range of garnish is 7, which can be deemed quite wide, but garnish offered as a separate group of meals often poses problems. Of course, it is possible to include the choice of garnish in the menu, but when offering a complete dish creation as meat-garnish-sauce, a separate category for garnish makes no sense. The average number of Hungarian type of vegetables is 0 in restaurants and roadside restaurants; 1 in small restaurants. The choice of this type of dishes is extremely poor. The lack of demand might also affect the scarcity of supply. At the same time, it would be vital the selection to include Hungarian type of vegetables prepared of high quality seasonal raw materials in a modern preparation way. Average numbers in case of salads: 6 in restaurants, 8 in small restaurants and roadside restaurants. In accordance with Hungarian traditions, offering 6-8 different salads, which includes also pickles, is typical. In this case, pickles (including pickled cucumber, pickled green pepper, etc.) can be listed in one group, and still the selection might be unique. Should this be the case, of course these pickles must be offered at the same price. By the similar principle, salads (tomato, cucumber, etc.) could be listed in a different line. Average number of sauces is 0 in case of restaurants, 1 in small restaurant, while 2 in roadside restaurants. Here comes the question: Why it is necessary to include a separate group of dishes of sauces.

The total values of cheese, cold desserts, warm sweets and canned fruits (based on the data of 50 restaurants, 18 small restaurants and 11 roadside restaurants) indicate that the average number of cheeses is 0 both in restaurants and in roadside restaurants and 1 in small restaurants (see Fig. 8). The number of cheeses appearing in menus is quite low, but catering units occasionally offer a selection of cheeses including more types of cheese. The average number of cold desserts is 3 . This figure is acceptable. The average number of warm sweets is 4 in restaurants, 6 in small restaurants and 7 in roadside restaurants. The width of range of warm sweets is 7 in roadside 
restaurants, a rather high figure. The average range of fruits and canned fruits is 0 in restaurants, 1 in small restaurants and 0 in roadside restaurants. These figures are quite meaningful. At least 1 kind of fruit should be offered in every type of restaurants.

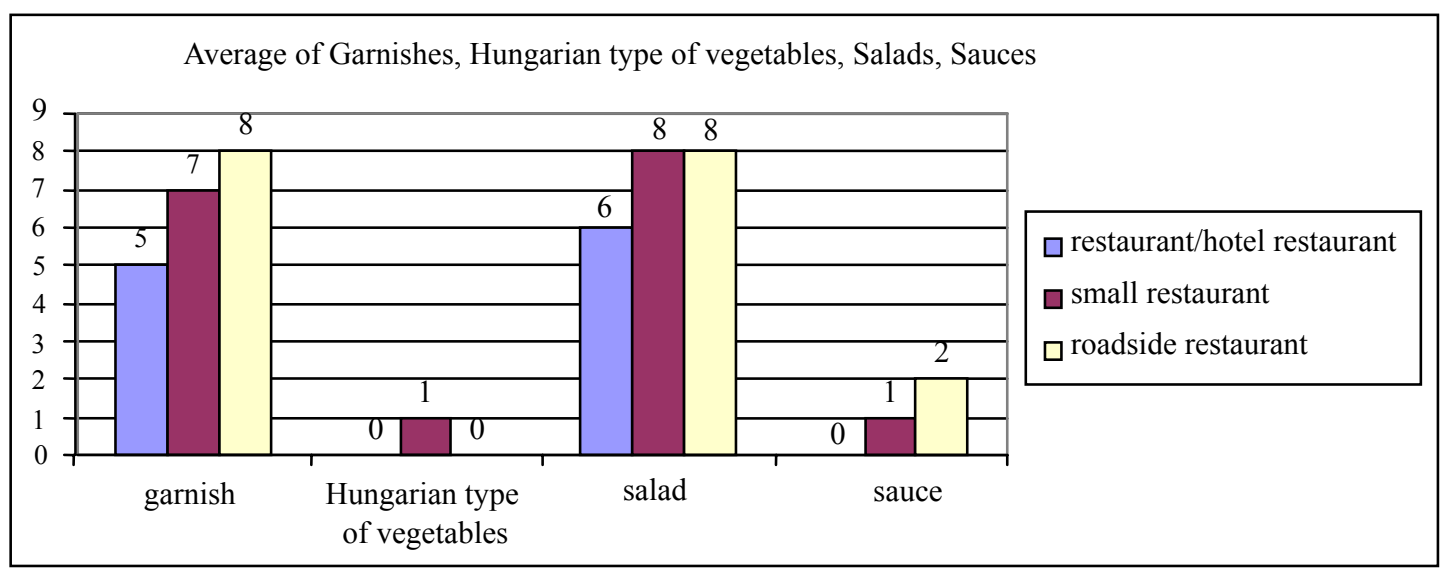

Fig. 7 Average number of garnish, Hungarian type of vegetables, salads and sauces in different hot cuisine catering units Data source: own research.

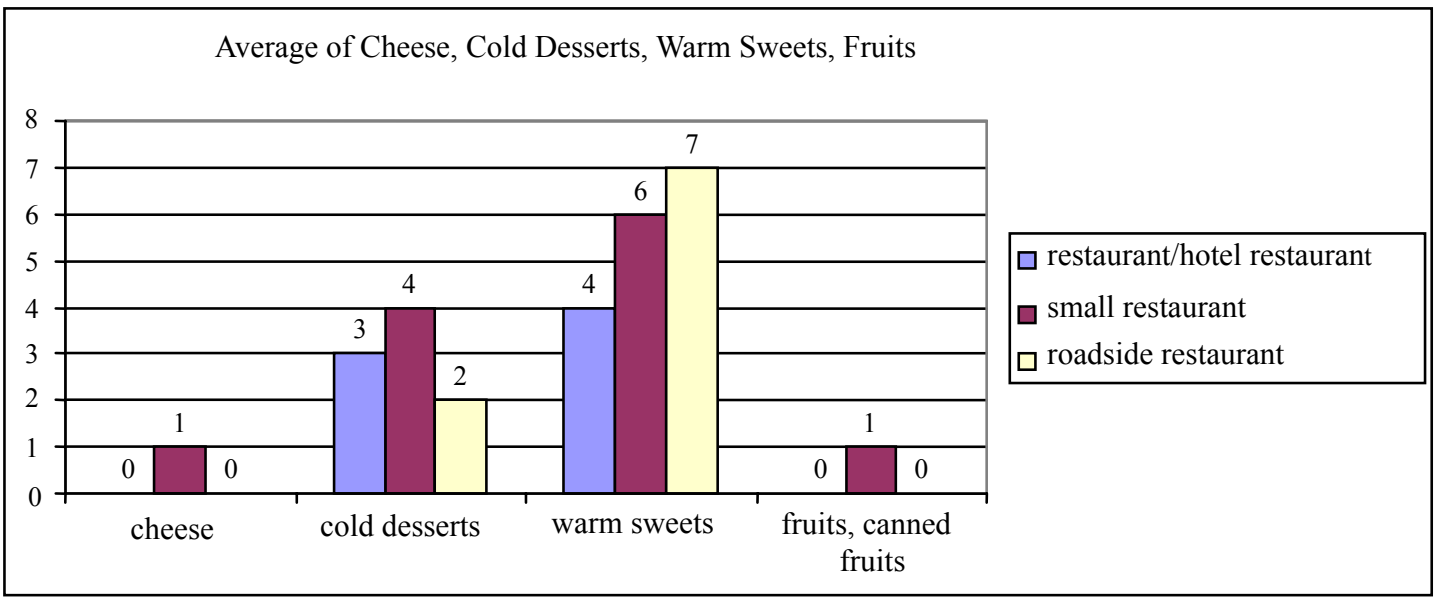

Fig. 8 Average number of cheese, cold desserts, warm sweets, fruits and canned fruits in the different hot cuisine units Data source: own research.

\section{Results}

After processing the data from 79 menus, the primary goal of surveying the choice of dishes in the region can be summarized as follows: The quality of menus in terms of their content reflects a quite diverse picture. There are restaurants where guests are awaited with more than 200 different dishes. In-depth analyses suggest that producing such a wide range of meals at a consistently high level is a great challenge for any kind of hot cuisine unit regardless of venue and time.

Among the studied units, however, Mirror Restaurant Astoria Hotel, Budapest is one of those operating with the highest quality offering altogether 39 dishes excluding sandwiches and snacks, but its menu is a unique, professional curiosity. Managing raw materials is simpler this way, and this makes consistently preparing dishes of high quality easier. 
In some cases, dish groups are listed in menus in an order fashionable some decades ago. As a consequence of this, guests may encounter desserts earlier than main courses or salads.

It is also rather old fashioned to use the categories of readymade dishes and freshly made dishes. Foreign speaking guest may think in this case that the translated denomination of readymade dishes might refer to "meals not cooked at that time". At the same time, several hot cuisine units apply logical listing order of the meals—based on the timeline of consuming.

Fortunately, nearly a hundred dishes prepared of Hungarian raw materials including goose liver, goose cracklings, ewe cheese, goat cheese and curd etc. can be found. Regional dishes appear on the menus only at an insignificant frequency. Out of the 6000 dishes surveyed, only 20 dishes can be somehow connected to a given region. Often only the denomination of the dish refers to its regional character, e.g., Szentendre Fish Platter, Danube Fish Wooden Plate, Bundle of Pilis and Monor Robbers' Meat.

In accordance with Hungarian traditions, dishes starting the meal (cold/warm starters and soups) are dominated first of all by soups. With regards to main courses in restaurants and in small restaurants, the number of poultry dishes is the highest, while in roadside restaurants the same stands true for pork and poultry dishes. Basic supply of vegetarian dish is still one-sided and quite limited (including only breaded cheese and mushroom).

The range of garnish covers 7 different types on the average, however, the question may arise-Why catering units don't offer directed main course-garnish pairs? As of international practise, main course is a complete dish including meat (or without meat), garnish and sauce. Fortunately, some of the surveyed menus included no separate garnish category. Strange and surprising, the number of Hungarian type of vegetables is less than minimal, which is 0 in two types of units (restaurants, roadside restaurants), while in small restaurants is 1 . On the other hand, the average number of salads offered to main courses is 6 in restaurants, while in small restaurants and in roadside restaurants is 8 . The range of sauces is not too extensive as well, with an average of 1: 0 in restaurants; 1 in small restaurants and 2 in roadside restaurants. In addition, as it has already been mentioned in the analysis of the South Transdanubian Region, the composition of the most often appearing Tartare sauce is not exactly identical with the sauce offered in international cuisines.

The average choice of cheese is 0 in restaurants and roadside restaurants, and 1 type of cheese is usually offered in small restaurants. The standard favourite of cold desserts are ice cream cups, sponge cake Somlo style and chestnut puree, which latter is representing a smaller rate in comparison the previous regions. Warm sweets are dominated by pancakes (50\%) largely contributing to the base of this category. In the choice of restaurants, strudel has a quite significant role. The choice of fruits, including also canned fruits, is rather narrow, the average figure being 0 in restaurants, 1 in small restaurants and 0 in roadside restaurants. Why are tasty Hungarian fruits missing from the menu?

An improvement can be detected in the fact that more hundreds of different dish versions are offered in restaurants, small restaurants and roadside restaurants. There are some places where interesting fantasy names are given to these dishes, e.g., Favourite of Young Sheperd or of Szepi.

In many cases, there are formal mistakes in the menus, e.g., the name of the place, the manager name or the name of the chef are missing, the word classification is used instead of categorization which was the terminology on force in the surveyed period, etc. Also, spelling mistakes and misuse of terminology often appear in the menus, e.g., "baconszalonna", caviar, tuna fish, Gordon blue, beafsteak, etc. The proper use of these terms is as follows: bacon (or "húsos szalonna"). Caviar is the roe of a certain species of fish, namely sturgeon, otherwise, it should be named salted roe or salmon caviar in case of salmon. Frozen fillet of sea fish is often referred to as tuna fish but 
these are generally hake fillets. The proper name of the dish is Cordon Bleu, while it should be spelt as beefsteak in Hungarian menus.

\section{Conclusion and suggestions}

The following conclusions may be made from the analysis of choice of dishes offered in the menus of 50 restaurants, 18 small restaurants and 11 roadside restaurants in the years 2005-2008:

- A too extensive range of dishes listed in the menu may have an adverse effect on preparing dishes in consistently high quality;

- It would be practical to keep selection within reasonable limits at the same time providing outstanding quality dishes for the guests;

- Applying international menu formatting experience would be useful;

- The terms "Readymade dishes" and "Freshly made dishes" should not be used any more, instead, dishes should be included among main courses based on their main raw material;

- Range of vegetarian dishes should be extended and made more diverse, and tasty Hungarian type of vegetables dishes should be prepared with less or no "roux" (thickening agent of flour and oil);

- The category of garnishes and sauces are not necessary when garnish and sauce are added to all main courses;

- Selection of cheese and fruits should be reasonably widened;

- Range of cold desserts should be made more flexible, there should be other desserts in addition to the magic trio of ice cream cup, chestnut puree and sponge cake Somlo Style;

- Pancake dominancy of restaurant warm sweets should also be weakened by expanding the choice of this category;

- Fantasy dishes cause no problem when an explanation of the dish is added;

- Range of regional dishes should be widened, since domestic and foreign tourists are mostly interested in local foods, accordingly, it is a shame that out of 6000 dishes only 20 can be attached to the region in any way;

- Adding the name of a geographic location to that of the dish does not make the food an authentic local speciality in itself;

- It is recommended to include traditional foods in the menus by applying professional literature and the related knowledge of local people;

- Using local traditional and regional raw materials is an outstanding possibility for expanding the range of regional dishes. Some of the local traditional and regional raw materials can be seen in Fig. 9.

Traditional and regional raw materials, products of the Budapest-Middle-Danube Region: delicacy grapes of Buda, apricot of surroundings of Budapest, chestnut of Nagymaros, cherry of Pomáz, strawberry of Island of Szentendre, red current of Szob, champignon of Budafok, cabbage and sauer kraut of Vecsés.

- A further possibility is to use local wines when preparing the dishes, however, it is not enough to indicate only "wine" in the menu, it should be detailed, e.g., Fish Soup with 2007 of Etyek Country house Rosen garden cellar;

- Areas to improve the most include the usage of an extremely limited range of raw materials and preparation methods, menu compositions often lacking creativity;

- Therefore, it would be practical to dismiss the most regular choice of dishes available in almost each and every restaurant and offer regional dishes prepared of local raw materials in the menus;

- More attention should be paid to meeting the formal and spelling requirements of the menus; 
- All in all, current choice of dishes should be updated and a wider range of regional dishes should be offered.

The above goals require the cooperation of all professionals in their everyday practise to observe our traditions in the future as well.

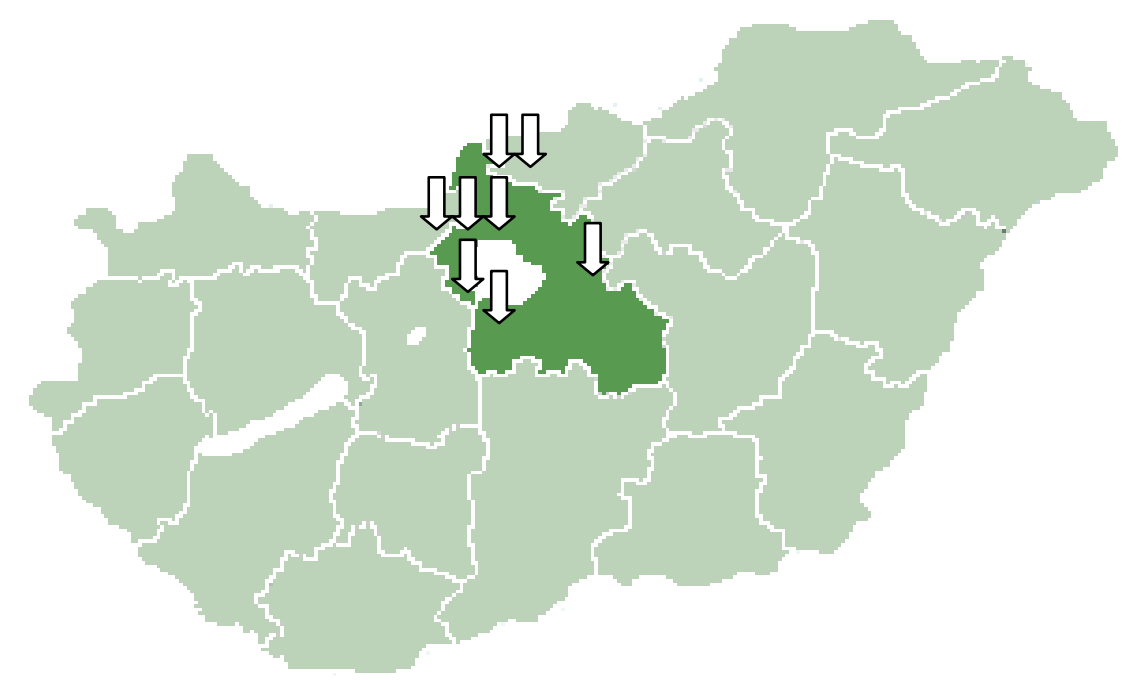

Fig. 9 Traditional and regional raw materials and products in the Budapest-Middle-Danube Region

Data source: http://commons.wikimedia.org/wiki/File:PestCounty.gif. and own research.

\section{References:}

Alsószopori, N. F.. (1926). Culinary cookbook of Transdanubia. Szombathely: Pannon Publishing Company, 313.

Category rules of catering establishment. (1998). Departmental Order, Budapest.

Farnadi, É., et al. (2002). Traditions-flavors-regions program. Ministry of Agriculture, Centre of Agro Marketing, Budapest, 365.

Sándor, D.. (2002). Food knowledge. Budapest Business School, Budapest, 323.

Sándor, D.. (2008). Appearance of regional dishes in the food choice of the Southern Transdanubian touristic region. Scientific Yearbook, Budapest Business School, Budapest, 194-208.

Sándor, D.. (2009a). Analysis of Transdanubian supply of dishes-Local raw materials, dishes. College of Szolnok, Economica Scientific Publications, Szolnok, 50-57.

Sándor, D.. (2009b). Appearance of regional dishes in the food choice of the Southern Transdanubian touristic region. Hungarian Tourism Bulletin, Budapest, 14-18.

Sándor, D.. (2009c). Local ingredients and regional dishes in the choice of the Middle Transdanubian touristic region. Culinary Journal of Gastronomic and Hotel, Budapest, 28-29.

Szigeti, A.. (2003). Popular cuisine dishes of Transdanubia. Budapest: Agriculture Publishing Company, 384.

(Edited by Ruby and Chris) 